\title{
OPTIMALITY OF THE REARRANGEMENT INEQUALITY WITH APPLICATIONS TO LORENTZ-TYPE SEQUENCE SPACES
}

\section{Fernando Albiac, José L. Ansorena, Denny Leung and Ben Wallis}

Abstract. We characterize the sequences $\left(w_{i}\right)_{i=1}^{\infty}$ of non-negative numbers for which

$$
\sum_{i=1}^{\infty} a_{i} w_{i} \quad \text { is of the same order as } \sup _{n} \sum_{i=1}^{n} a_{i} w_{1+n-i}
$$

when $\left(a_{i}\right)_{i=1}^{\infty}$ runs over all non-increasing sequences of non-negative numbers. As a by-product of our work we settle a problem raised in [1] and prove that Garling sequences spaces have no symmetric basis.

Mathematics subject classification (2010): 26D15, 46B15, 46B20, 46B25, 46B45.

Keywords and phrases: Sequence spaces, Garling spaces, Lorentz spaces, symmetric basis, rearrangement inequality.

\section{REFERENCES}

[1] F. Albiac, J. L. Ansorena, B. Wallis, On Garling sequence spaces, arXiv:1703.07772 [math.FA].

[2] F. Albiac, N. J. Kalton, Topics in Banach space theory, Graduate Texts in Mathematics, vol. 233, Springer, [Cham], 2016.

[3] G. H. Hardy, J. E. Littlewood, G. Pólya, Inequalities, Cambridge Mathematical Library, Cambridge University Press, Cambridge, 1988. Reprint of the 1952 edition. 